\title{
Nano-Colin Material and Its Effective on the Compaction Factor for Sandy Soil
}

[Mahmoud M. Abu zeid ${ }^{1}$, Abdeen M. El Nagar ${ }^{2}$

\author{
${ }^{1}$ Civil Engineering Department, Faculty of Engineering, Qena, South Valley University, Egypt. \\ ${ }^{2}$ Housing and Building National Research Centre (HBRC), 87 El-Tahrir St., Dokki, Giza, P.O. Box 1770 Cairo, Egypt ]
}

Abstract - This study deals with the effect of addition of nanoColin on some properties of the soil compared Properties obtained from tests carried out on samples. characteristics were obtained from tests conducted on normal sandy soil samples with those obtained from tests performed on the same samples after the addition of nano Colin them. Was a standard proctor test record on the sandy soil used samples (replacement) and we got the laboratory maximum dry density value, After that we have implemented a sand cone method for in situ density and compaction of which we got a coefficient before the addition of nano-Cullen and show us that compaction factor ratios ranging from 95.3 to $96.8 \%$ of the value of the laboratory maximum dry density. After mixing the material nano Colin sandy soil in a certain way and at rates ranging from 3- $4 \mathrm{~g} / \mathrm{m} 3$ of sand were carried sand Cone method experience of on them for compaction factor become clear to us increase the value of density in situ at a rate ranging from $\mathbf{1 5 - 2 0}$ percent of what it was before the addition of nano-Cullen . The results of testing the effect of nanoColin on samples that have been. decrease value ratio blanks from 0.62 to 0.56 of the soil blended nano-textured Colin.ankhvd substitution layer thickness used $1.0 \mathrm{~m}$ to $0.5 \mathrm{~m}$ at a rate of $50 \%$ after the addition of nano-Collen. A significant reduction of the value of the economic cost per cubic meter was observed case and found that it reduced by $15 \%$, including the price of the material used and the cost of all tests conducted in the laboratory of soil mechanics and foundations, Faculty of Engineering in Qena South Valley University - Egypt and field tests were also within the college of engineering Qena. The results showed the compaction nature of soil get increase compaction factor and stress characteristics with adding nano materials.

Keywords - Nano technology, Synthesis, Nano kaolin, Soil, compaction factor, sand bottle.

\section{Introduction}

The nanotechnologies idea was suggested by Richard Feynman for the first time in 1959, after that, this technology developed in all branch of sciences. However national pioneers of nanotechnology in United States have presented a comprehensive definition of this technology (NNI 2007):

1. Research and technology development at the atomic, molecular, or macromolecular levels, at a length scale of approximately 1 to 100 nanometers (a nanometer is one billionth of a meter, too small to be seen with a conventional laboratory microscope);

2. Creation and use of structures, devices, and systems that have novel properties and functions because of their small and/or intermediate size, at the level of atoms and molecules;

3. Ability for atomic-scale control or manipulation. Chemical reactions occur in nano scale.

As a result of this fact, there is a great potential of nanotechnology's application in soil mechanics including seepage, grouting, soil stabilization and etc. Bearing capacity is the ability of soil to safely carry the pressure placed on the soil from any engineered structure without undergoing a shear failure with accompanying large settlements. Applying a bearing pressure which is safe with respect to failure does not ensure that settlement of the foundation will be within acceptable limits. Therefore, settlement analysis should generally be performed since most structures are sensitive to excessive settlement, after Mahmoud M. Abu zeid and Abdeen M. El Nagar $\{1\}$.

Mixture of soil with some special additive could improve the soil strength parameters, and this procedure has been performed in the past for stabilization and improvement of weak soils.

The main strategy of nanotechnology in geotechnical engineering is the improvement of soil parameters with application of nano materials. The presence of only small amount of nano material in the soil by volume could influence significantly the physical and chemical behavior of soil due to a very high specific surface area of nano materials, surface charges and their morphologic properties.

The use of stabilization techniques has increased significantly in recent decades owing to new construction sites, increasingly being located in areas of poor quality ground. It is suggested that ground improvement will be critically important in future geotechnical practices to adopt cost-effective solutions, to achieve reductions in quantities of material used and etc. [2]. One of the extensively used techniques for the improvement of problematic soils in relatively tropical countries is soil treatment with customary cementitious additives such as cement, lime and fly ash [3].

In recent years, nano particles have attracted considerable scientific interest for many civil engineering applications. The types of nano particles that are most commonly used in cementitious composites are $\mathrm{SiO2}, \mathrm{TiO} 2, \mathrm{Al} 2 \mathrm{O3}$, and carbon nano tubes [4]. all the introduced nano particles plays the most significant role. Furthermore, nano particles accelerate hydration of cement due to its high surface energy [5]. Also, nano materials cause physical alterations such as improvement in the packing density which corresponds to filling effect of its particles [6]. 
Proc. of the Fifth International Conference on Advances in Civil, Structural and Environmental Engineering - ACSEE 2017. Copyright $\odot$ Institute of Research Engineers and Doctors. All rights reserved.

ISBN: 978-1-63248-122-1 doi: 10.15224/ 978-1-63248-122-1-03

In the limited investigation performed in this field, the effects of nano materials in engineering properties of soil have been considered mainly in two aspects including the effect of the presence of natural nano particles in the soil and the effect of adding nano materials in to the soil. In this way, the effect of natural nano particles in the engineering properties of soil. He found that the presence of only a small amount of Nano particles in the soil have significant effect in the physical and chemical behavior and engineering properties of soil. He also concluded that the soils including nano particles with intra particle voids in nano scale, usually demonstrated the higher liquid and plastic limits, and the presence of fibrous nano particles enhances the soil shear strength (1).

Soil stabilization is one of the oldest ground improvement techniques. Soil stabilization is the process of improving the engineering properties of soil and thus making it more stable. It is required, when the soil available for construction is not suitable for the intended purpose. Soil stabilization is used to reduce the permeability and compressibility of the soil mass in earth structures and to increase its shear strength and bearing capacity of foundation soils.
Stabilization is the process of improving the properties of soil by changing its gradation. Two or more types of natural soils are mixed to obtain a composite material which is of superior to any of its components. To achieve the desired grading, sometimes the soils with coarse particles are added or the soils with finer particles are removed.

The blended soil possesses both internal friction and cohesion. When properly placed and compacted, the blended material becomes stable and also load carrying capacity is increased. The main objective of soil stabilization is to increase the strength of soil and to reduce the construction cost by making best use of the locally available materials. However the main use of soil stabilization is to improve the natural soils for the construction of highways and airfields, the principle of soil stabilization is used for the controlling the grading of soils and aggregate in the construction of bases and sub base of the highways and airfields As a recent advancement, nano particles are used as an additive to the soil and researches are going on to find its effects in soil.

\section{Materials}

The materials used in this investigation are Kaolin which is collected from Sinai, west of Gebel Gunna, Egypt. Nanoscale kaolin particles were prepared in the Housing and Building National Research Center (HBRC) labs from the kaolin raw. The chemical composition of nano kaolin shown in Table (1), after Mahmoud M. Abu zeid and Abdeen M. El Nagar $\{1\}$.

Table (1): The chemical composition of nano kaolin material.

\begin{tabular}{|c|c|c|c|c|c|c|c|c|c|c|c|c|}
\hline Materials & $\mathrm{SiO}_{2}$ & $\mathrm{AI}_{2} \mathrm{O}_{3}$ & $\mathrm{Fe}_{2} \mathrm{O}_{3}$ & $\mathrm{CaO}$ & $\mathrm{MgO}$ & $\mathrm{SO}_{3}$ & $\mathrm{Na}_{2} \mathrm{O}$ & $\mathrm{K}_{2} \mathrm{O}$ & $\mathrm{TiO}_{2}$ & $\mathrm{P}_{2} \mathrm{O}_{5}$ & Loss & TOTAL \\
\hline Nano-kaolin & 56.16 & 38.19 & 0.37 & 0.08 & 0.38 & 0.17 & 0.00 & 0.04 & 1.12 & 0.26 & 3.13 & 99.89 \\
\hline
\end{tabular}

\section{Experimental work}

\subsection{Synthesis of Nano- Kaolin}

Nano-kaolin particles are synthesized by firing the high pure kaolin material at 800 oC for $2 \mathrm{~h}$ with a heating rate of $5 \mathrm{oC} / \mathrm{min}$ to form an amorphous nano precursor. Firing of the raw kaolin provided to the formation of nano clay particles with the average particle size $50-100 \mathrm{~nm}$. The kaolin raw material before firing has a grain size about $100 \%<10 \mu m$ as indicated from the TEM (Fig. 1). Fig. (2) The XRD patterns of nano- kaolin material, after Mahmoud M. Abu zeid and Abdeen M. El Nagar $\{1\}$.

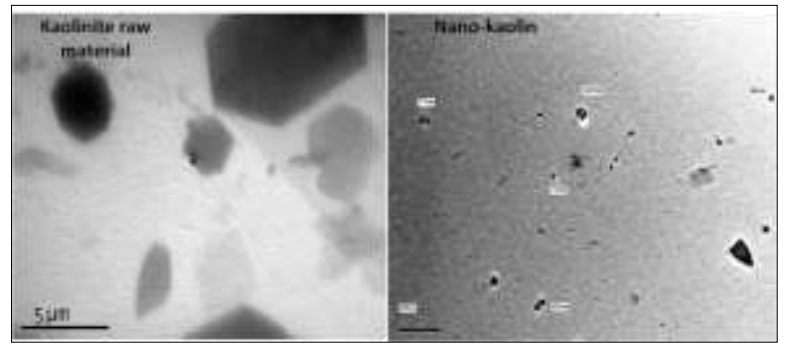

Fig. (1): Transmission electron micrographs of the kaolin (left) and nano- kaolin (right) materials. after

Mahmoud M. Abu zeid and Abdeen M. El Nagar $\{1\}$. 


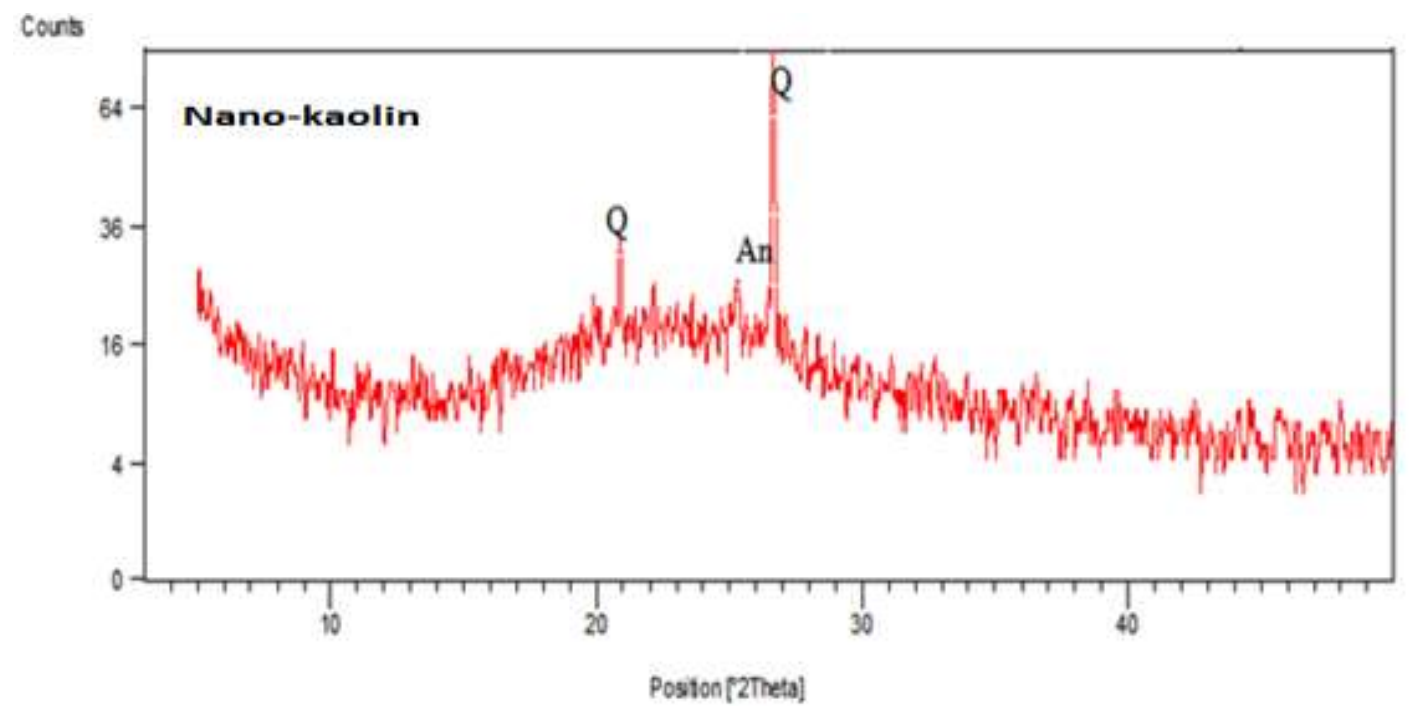

Fig. (2): X-ray diffraction patterns of nano kaolin material. [Q=Quartz An=Anataze].

The XRD pattern of the nano-kaolin shows distorted and dehydrated type forming amorphous nanokaolin material. The main kaolin beak destroyed after firing the high pure kaolin material at 800 oC for $2 \mathrm{~h}$ with a heating rate of $5 \mathrm{oC} / \mathrm{min}$.

Nano material mixing with water by stirrer for 10 minutes firstly to have good dispersing in soil materials then adding to soil layers.

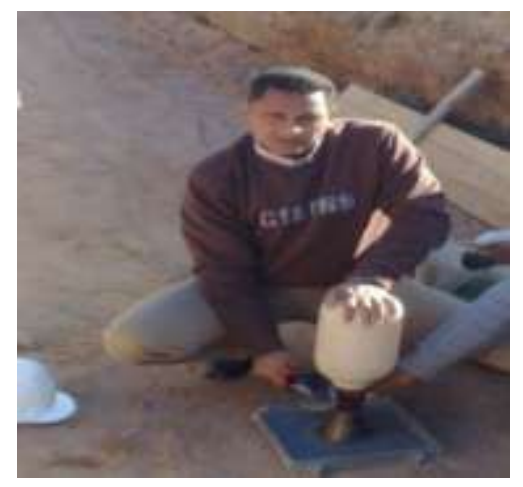

Fig. (4): Sand cone method in the Field, after Mahmoud.M.Abuzei

\section{Results and analysis}

The general location and places of tests and relationship between maximum dry density and optimum moisture content, present the results of the experiment to demonstrate the behavior of replacement soil established under the influence of compaction before and after add Nano- Kolin material. Conducted the Sand Bottle test on six points at the site to determine the first layer (field density, Proctor test results. The weight of the volume unit of standard sand, The weight of the volume unit of the standard sand was determined by the results in Table (1). The weight of the sand that dictated the cone was determined by the results in Table (2), Determination of dry soil density $\left(\gamma_{\text {dry }}\right)$ for extracted samples: 
Proc. of the Fifth International Conference on Advances in Civil, Structural and Environmental Engineering - ACSEE 2017. Copyright (c) Institute of Research Engineers and Doctors. All rights reserved.

ISBN: 978-1-63248-122-1 doi: 10.15224/ 978-1-63248-122-1-03

The results were presented in Table (3) according to the Egyptian code for mechanics, design and implementation of the foundations. Therefore, the dry density $\left(\gamma_{d r y}\right)$ was calculated and the results were recorded in the tables. $(4,5)$.

Table (2): determine The weight of the sand that filled the cone

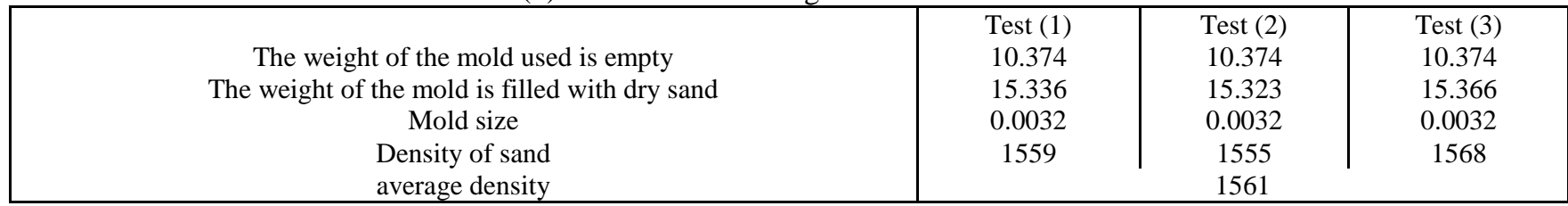

Table ( 3):Find weight of the sand that fills the cone

The weight of the plastic package + cone + sand before the experiment

The weight of the plastic package + cone + sand after the experiment

The weight of the sand that fills the cone average density

\begin{tabular}{|c|c|c|}
\hline Test (1) & Test (2) & Test (3) \\
7.550 & 7.393 & 7.396 \\
5.929 & 5.792 & 5.834 \\
1.621 & 1.601 & 1.562 \\
& 1.595 & \\
\hline
\end{tabular}

Table (4):Results of modified proctor test

\begin{tabular}{|c|c|c|c|c|c|}
\hline Test (N0.) & 1 & 2 & 3 & 4 & 5 \\
\hline $\operatorname{Mold} \operatorname{size}\left(\mathrm{m}^{3}\right)$ & 0.000942 & 0.000942 & 0.000942 & 0.000942 & 0.000942 \\
\hline The weight of the template used is empty +base $(\mathrm{Kg})$ & 6.614 & 6.614 & 6.614 & 6.614 & 6.614 \\
\hline $\begin{array}{l}\text { The weight of the template used is empty }+ \text { base }+ \text { compacted } \\
\text { sample }(\mathrm{Kg})\end{array}$ & 8.733 & 8.784 & 8.804 & 8.815 & 8.835 \\
\hline weight of the compacted sample $(\mathrm{Kg})$ & 2.119 & 2.170 & 2.190 & 2.201 & 2.221 \\
\hline Density of weight sample ( & 2249 & 2304 & 2325 & 2337 & 2358 \\
\hline Water content $\%$ & 4 & 5.1 & 5.7 & 6.4 & 8.8 \\
\hline Sample dry density & 2163 & 2192 & 2199 & 2196 & 2167 \\
\hline
\end{tabular}

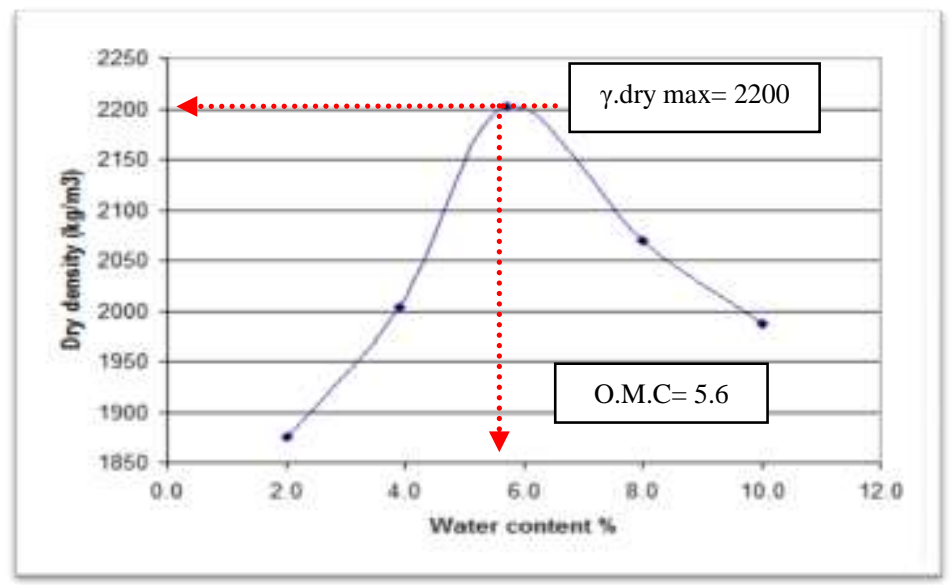

Fig (3): relation between dry density and water content

Determination of dry density and water content for outset sample before add Nano-Kaolin

Table (5): determine water content for field sample from point $(1-6)$ before adds Nano- Kaolin

\begin{tabular}{|c|c|c|c|c|c|c|}
\hline Point (No.) & 1 & 2 & 3 & 4 & 5 & 6 \\
Weight of sand bottle +cone + & 6.550 & 6.320 & 6.210 & 6.311 & 6.260 & 6.820 \\
sand before test & & & & & & \\
Weight of sand bottle + cone + & 3.401 & 3.182 & 3.061 & 3.520 & 3.008 & 3.900 \\
sand after test & 0.000996 & 0.000989 & 0.000996 & 0.000766 & 0.001062 & 0.000849 \\
Volume of hole & 2.200 & 2.180 & 2.166 & 1.735 & 2.365 & 1.833 \\
Weight of soil outed from hole & 2209 & 2205 & 2175 & 2264 & 2227 & 2159 \\
Density of field soil & 3.4 & 4.2 & 3.7 & 4.5 & 3.5 & 2.9 \\
Water content & 2135 & 2101 & 2102 & 2121 & 2122 & 2114 \\
Field density &
\end{tabular}


Proc. of the Fifth International Conference on Advances in Civil, Structural and Environmental Engineering - ACSEE 2017. Copyright $\odot$ Institute of Research Engineers and Doctors. All rights reserved.

ISBN: 978-1-63248-122-1 doi: 10.15224/ 978-1-63248-122-1-03

Determine of compaction factor, Compaction factor determination according to Egyptian code for soil mechanics and foundation

Table (6): determine compacted factor from point $(1-6)$ before add Nano- Kaolin

\begin{tabular}{|c|c|c|c|c|c|c|}
\hline Point (No.) & 1 & 2 & 3 & 4 & 5 & 6 \\
$\begin{array}{c}\text { Dry density of field soil } \\
\begin{array}{c}\text { Maximum dry density according proctor test } \\
\text { Compaction factor }\end{array}\end{array}$ & 2135 & 2101 & 2102 & 2121 & 2122 & 2114 \\
\hline
\end{tabular}

Table (7): determine water content for field sample from point (1 - 6) after add Nano- Kaolin

\begin{tabular}{|c|c|c|c|c|c|c|}
\hline Point (No.) & 1 & 2 & 3 & 4 & 5 & 6 \\
Weight of sand bottle +cone + & 6.633 & 6.556 & 6.490 & 6.377 & 6.395 & 6.362 \\
sand before test & & & & & & \\
Weight of sand bottle + cone + & 3.766 & 3.932 & 3.792 & 3.141 & 3.632 & 3.500 \\
sand after test & 0.000815 & 0.000659 & 0.000707 & 0.001052 & 0.000749 & 0.000812 \\
Volume of hole & 1.801 & 1.441 & 1.541 & 2.315 & 1.652 & 1.787 \\
Weight of soil outed from hole & 2209 & 2185 & 2180 & 2201 & 2207 & 2201 \\
Density of field soil & 3.5 & 4.0 & 3.7 & 3.8 & 4.0 & 4.1 \\
Water content & 2189 & 2195 & 2178 & 2167 & 2171 & 2191 \\
Field density &
\end{tabular}

Table (8): determine compacted factor from point $(1-6)$ after add Nano- Kaolin

\begin{tabular}{|c|c|c|c|c|c|c|}
\hline Point (No.) & 1 & 2 & 3 & 4 & 5 & 6 \\
Dry density of field soil & 2189 & 2195 & 2178 & 2167 & 2171 & 2191 \\
Maximum dry density according proctor test & \multicolumn{5}{|c|}{2200} \\
Compaction factor & $\mathbf{9 9 . 5}$ & $\mathbf{9 9 . 8}$ & $\mathbf{9 9 . 0}$ & $\mathbf{9 8 . 5}$ & $\mathbf{9 8 . 7}$ & $\mathbf{9 9 . 6}$ \\
\hline
\end{tabular}

\section{Conclusion}

After the work experience of the compaction on soil replacement board before and after the addition of nano kaolin shows us the relationship between the load and the amount of the decline and expense of carrying compaction factor of the soil that the material of nano kaolin by $0.3 \mathrm{~g} / \mathrm{m}^{3}$ lead to an increase in the compaction factor of the soil ranging from 45 $50 \%$ the result of them. These conclude that we can reduce the thickness of the layers replacement to $50 \%$, it is not easy because the mixing process are dry and then adding water and compacted in situ. Uneconomic terms and compared to the price of the soil in which they are available is expensive. Compaction factor increasing from 95.5 to $99.8 \%$, On the other hand Economically speaking, the use of Nano-Kolin material to the replacement soil leads to a decrease in the thickness of the replacement layers. In other words, without the use of Nano-Kolin material, the thickness of the layer is 1 $\mathrm{m}$. After the use of the Nano-Kolin material, the thickness of the layer is $0.5 \mathrm{~m}$.

\section{References}

[1]. Mahmoud M. Abu zeid, Abdeen M. El Nagar, Effect of nano-Kaolin on the bearing capacity of soil.

[2]. M.A. Galende, J. M. Becerril, M. T. Gómez-Sagasti, O. Barrutia L.

Epelde, C. Garbisu, A. Hernández. Chemical stabilization of metalcontaminated mine soil: early shortterm soil-amendment interactions and their effects on biological and chemical parameters. Water Air, \& Soil, 1825-1836. 2, (2014).
[3]. T. Murali Krishna, Sd. Shekun Beebi. Soil Stabilization by Groundnut Shell Ash and Waste Fiber Material. International Journal of Innovations in Engineering and Technology, 52-57, (2015).

[4]. Q.M. Manzoor, J. Mateo-Sagasta Jiménez, B. Siebe, C. Siemens, M. A. Hanjra. Environmental Risks and Cost-Effective Risk Management in Wastewater Use Systems. Wastewater springer, 55-72, (2015).

[5]. S. Horpibulsuk, C. Phetchuay, A. Chinkulkijniwat. Soil Stabilization by Calcium Carbide Residue and Fly Ash. J. Mater. Civ. Eng., 24(2): 184-193, (2012).

[6] Y.J. Du N.J. Jiang, S.Y. Liu, F. Jin, D.N Singh, A.J. Puppala. Engineering Properties and Microstructural Characteristics of Cement Stabilized Zinc Contaminated Kaolin. Canadian Geotechnical Journal, 51(3): 289- 302, (2014).

[7]. S. Horpibulsk, R. Rachan, A. Suddeepong, A. Chinkulkijniwat. Strength Development In Cement Admixed Bangkok Clay: Laboratory And Field Investigations. Soils and Foundations, 51(2):239-251, (2011).

[8]. Y. Liang, S.A. Bradford, J. Simunek, M. Heggen, H. Vereecken, E. Klumpp. Retention and Remobilization of Stabilized Silver Nanoparticles in an Undisturbed Loamy Sand Soil. Environ. Sci. Technol., 47 (21): 1222912237, (2013).

[9]. Heba Kamal El Dine Moustafa, Hebatalrahman Ahmed, Hesham Kamal Amin, Khalid Elzahabby. Study for Application of Artificial Neural Networks in Soil Stabilization by Nanotechnology,Seventh international conference on nano-technology in construction, Housing and Building National Research Center, Egypt, (2015).

[10]. G.V. Lowry, K.B. Gregory, S.C. Apte, J.R. Lead. Transformations of Nanomaterials in the Environment. Environ. Sci. Technol., 46 (13): 68936899, (2012).

[11]. Z.H. Majeed, M.R. Taha. Effect of Nanomaterial Treatment on Geotechnical Properties of a Penang Soft Soil. Journal of Asian Scientific Research 2(11):587-592, (2012).

[12]. A.A, Firoozi, M.R. Taha, A.A. Firoozi, T. Khan. Effect of Ultrasonic Treatment on Clay Microfabric Evaluation by Atomic Force Microscopy. Journal of Measurement.66: 244- 252, (2015). 